\title{
Disertación sobre la legitimidad moral de las fronteras en los contextos del siglo XXI.*
}

\author{
Dissertation on the moral legitimacy of the \\ borders in the contexts of the XXI century.
}

Eduardo Elías Gutiérrez López**

\section{Resumen}

El fenómeno migratorio ha acompañado a la humanidad durante todas las etapas y transiciones políticas, sociales y económicas, pero recientemente se ha acentuado con eventos coyunturales como el éxodo de personas migrantes centroamericanas que llegó a México a finales de 2018. Estos hechos han revivido un debate filosófico que cuestiona la legitimidad de las fronteras, basado en que, a través de ellas, se convalidan jurídicamente desigualdades de toda clase. En este trabajo se evalúa la existencia -y pertinencia- de las fronteras jurídico-administrativas a partir de algunas doctrinas morales como el deontologismo, el utilitarismo y el primado de la voluntad; así como de algunas corrientes de la filosofía del derecho (iusnaturalismo) y de la sociología. El objetivo es responder, a partir de todas las doctrinas analizadas, las dos siguientes preguntas: ¿Cómo se trata actualmente a las personas migrantes que ingresan a un país que

\footnotetext{
* Artículo de Reflexión.

* * Profesor e investigador adscrito a la Universidad Autónoma de Baja

California.elias.gutierrez@uabc.edu.mx
} 
no es el de su origen y no lo hacen por las vías regulares existentes? ¿Desde cuál teoría ética se sostiene el rechazo de personas migrantes a un país distinto al de su origen?

\section{Palabras clave:}

Fronteras, migración, moral, legitimidad, soberanía.

\section{Abstract}

The migratory phenomenon has accompanied humanity through all stages and political, social, and economic transitions, but it has recently been accentuated by conjunctural events such as the exodus of Central American migrants that arrived in Mexico at the end of 2018. These events have revived a philosophical debate that questions the legitimacy of borders, based on the legal recognition of inequalities of all kinds. In this paper the existence -and relevance- of juridical-administrative borders is evaluated from some moral doctrines such as deontology, utilitarianism and the primacy of the will; as well as from some currents of the Philosophy of Law (natural law) and of Sociology. The aim is to answer, on the basis of all the doctrines analyzed, the following two questions: How are migrants who enter a country other than their country of origin currently treated and do not do so through the existing regular channels? From what ethical theory is the rejection of migrants to a country other than their origin supported?

\section{Key words:}

Borders, migration, moral, legitimacy, sovereignty. 


\section{Introducción}

La migración es un tópico que data de mucho tiempo en México, principalmente por la histórica salida de mexicanos hacia los Estados Unidos; sin embargo, se ha intensificado en los últimos años a raíz del tránsito frecuente de personas de Centroamérica y de otros países. Estas transformaciones de la realidad social han demandado del Estado Mexicano una gama de reconfiguraciones en su política migratoria, para asimilar que la migración es un fenómeno multidimensional, y que México experimenta todas sus dimensiones: origen, destino, tránsito, retorno y refugio de personas migrantes. De hecho, esta multidimensionalidad sería uno de los fundamentos - de acuerdo con la exposición de motivos de tal ordenamiento legal- que darían origen a la Ley de Migración en México, publicada en el Diario Oficial de la Federación el 25 de mayo de 2011.

El último trimestre de 2018 en México fue especialmente relevante en el estudio de la migración, más de seis mil personas procedentes de Centroamérica habían llegado a suelo mexicano: niñas, niños, familias, jóvenes, etcétera, la gran mayoría con la intención de llegar a Estados Unidos (El Colegio de la Frontera Norte, 2018, p. 11). Estos hechos causaron división de opiniones, reflexiones desde lo político, lo jurídico y lo moral e incluso hubo espacio para el discurso de odio y los pronunciamientos discriminatorios. Durante el mes de noviembre de 2018 se organizaron y materializaron por lo menos dos marchas en Tijuana, Baja California, con la consigna de expresar un rechazo e inconformidad hacia el arribo de las comunidades centroamericanas que viajaban en el éxodo.

México constituye geográficamente el último espacio que deben transitar las personas centroamericanas para llegar a Estados Unidos, por consiguiente, las sociedades de esta región están relacionadas de modo consuetudinario con estas dinámicas de movilidad humana. Empero, el éxodo de personas migrantes centroamericanas 
que arribó a diversas ciudades del norte del país, y principalmente a Tijuana durante el último periodo de 2018, contaba con dimensiones demográficas inusitadas y un seguimiento mediático -nacional e internacional- notoriamente influyente en la percepción colectiva sobre este suceso.

Las caravanas en México no son un fenómeno novedoso, ya que, por ejemplo, de manera ininterrumpida y desde 1999 se ha llevado a cabo la Caravana de Madres Centroamericanas, que tiene como consigna la búsqueda de la verdad respecto a migrantes desaparecidos en territorio mexicano. Asimismo, en 2011 se realizó la Caravana Paso a Paso hacia la Paz para denunciar los secuestros de personas migrantes en México, $y$, finalmente, y de modo continuo desde 2014, se realiza el Vía Crucis Migrante (Vargas, 2018, p. 129).

La filosofía del derecho como una rama analítica de la ciencia jurídica puede aportar a la reflexión, a la búsqueda de respuestas y al análisis de un tema como la migración no solo desde lo teórico, sino también desde la praxis política o jurídica. Este trabajo tiene como objetivo discutir algunos aspectos que dentro del "consenso jurídico" se creían resueltos, pero que fenómenos como el presentado en México a finales de 2018 -el éxodo de migrante centroamericanos- incitan a una nueva discusión sobre la justificación moral y legitimidad de las fronteras.

\section{Reflexiones conceptuales sobre soberanía y fronteras}

Desde la composición formal de los Estados-nación, el territorio ha sido uno de sus cuatro elementos fundamentales, además de la sociedad humana, el orden jurídico y el poder soberano (Porrúa, 2005, p. 198). En tal sentido, la existencia de las fronteras es contemporánea a la organización misma de las sociedades en entidades estatales. Los enfoques desde los que se han estudiado las fronteras 
(los estudios sobre Geografía, el Derecho Internacional Público y, recientemente, los Estudios de Migración) desde su origen han tenido entre sus propósitos: a) establecer sus límites territoriales, b) comprender sus términos regulatorios y c) analizar las vías por las que las personas pueden traspasarlas de forma regular.

Todos estos enfoques parten de la premisa de que la existencia de las fronteras es una cualidad imprescindible en la organización de los Estados-nación, por lo que no sería necesario cuestionar su justificación moral o legitimidad.

La existencia de fronteras físicas o líneas divisorias entre territorios por lo general tiene su basamento en los conceptos de soberanía y ciudadanía. Valdés $(2015$, p. 10) afirma que desde que se acuñó -a fines del siglo XVII- el concepto de soberanía como un derecho de los Estados-nación, fue comprendido como la capacidad reconocida que tienen para autogestionarse. A través de la práctica de esta autogestión se pueden legalizar diferencias basadas simplemente en una arbitrariedad como el lugar de nacimiento (Carbonell, 2008, p. 38), es decir, desconsiderar las eventualidades de lo que Rawls (2006, pp. 79-80) nombró: fortuna o lotería natural, que en este caso se traducen en el hecho de haber nacido en un contexto (político, social, económico, etc.) desfavorable y pretender salir de él o buscar uno distinto. Por ende, en estas prácticas autogestivas de los Estadosnación se admiten jurídicamente desigualdades a pesar de conocer las coyunturas.

Rawls (2006, pp. 79-80) acuñó el concepto de fortuna o lotería natural para referirse a aquellas condiciones que les eran asignadas a las personas de forma azarosa, es decir, que no partían de una elección propia, como ejemplo están: las habilidades, las capacidades o bien en el caso de la migración, el lugar de nacimiento (el cual nadie elige). 
Desde el punto de vista jurídico, los Derechos Constitucional e Internacional Público han subrayado que la justificación de las fronteras y su control descansa en una facultad soberana de los Estados-nación; sin embargo, esta facultad no solo se ha empleado para delimitar extensiones territoriales, sino también para admitir o excluir personas (Carens, 2009, p. 54). Aunque, como lo señala Morales (2017, p. 92), es probable que estas exclusiones no sean propiamente producto de la soberanía, sino de políticas de los Estadosnación en las que la usan como un argumento. Bustamante (2002, p. 165) ha hecho hincapié en varios de sus trabajos sobre la transición del modelo de soberanía absoluto al relativo, teniendo este último como principio central que su límite es la violación sistemática de los derechos humanos.

De allí que se hiciera la distinción entre soberanía absoluta y relativa; la primera "designa un poder ilimitado e ilimitable que habría de ser absoluto, ya que nadie podría limitarlo, ni aun siquiera ella misma” (Salas, 2000, p. 47), y la segunda se genera a partir de la evolución del Derecho Internacional Público, los nexos entre diferentes Estados-nación y, por consiguiente, la construcción de normas y acuerdos de naturaleza internacional vinculantes para los gobiernos estatales.

\section{La aparente contradicción dialéctica entre los derechos humanos y la soberanía de los Estados-nación}

Los derechos humanos tienen como fuente a las Constituciones de los Estados-nación, empero, con el auge del Derecho Internacional de los Derechos Humanos se terminó por reconocer la pertinencia de lo que Fix-Zamudio (2011, p. 25) llamaría: los derechos constitucionales internos de fuente internacional, al referirse a aquellos consagrados en los tratados internacionales de los que los Estadosnación son parte. Por consiguiente, de la relación entre estas fuentes 
(Constituciones y Tratados Internacionales) se constituye, de acuerdo con Bustamante (2018, pp. 258-259), una aparente contradicción dialéctica entre dos ejercicios soberanos de los Estados-nación: a) el de decidir desde sus Constituciones quién es nacional y quién es extranjero (a partir del reconocimiento jurídico de las fronteras), y b) el de admitir y obligarse a respetar una serie de estándares internacionales de derechos humanos en favor de las personas migrantes.

Esta contradicción dialéctica ha generado desacuerdos entre los derechos interno e internacional y entre los conceptos de soberanía nacional y derechos humanos. Sin embargo, las disputas entre un orden jurídico y otro internacional no tendrían sentido partiendo de la noción de que el segundo solo opera de forma complementaria cuando el primero fracasa, no existe o no funciona (Carpizo, 2012, p. 804).

Por su parte, la discordia entre soberanía nacional y derechos humanos guarda un dato digno de referir: los Estados-nación no emplean como escudo su poder soberano para coordinar entre ellos acuerdos para eliminar fronteras respecto al tránsito de capitales, información y servicios (globalización), y, en cambio, acuden a la defensa de su soberanía cuando se sustituyen estos flujos por personas migrantes (Sassen, 1996, p. 59 citado en Pécoud y de Guchteneire, 2005, p. 149).

\section{El impacto de la globalización en la reconfiguración de las fronteras}

El fenómeno de la globalización inmerso en múltiples áreas -incluida la entrada y salida de personas a través de diferentes fronteras- propicia estas probables contradicciones dialécticas, así como disputas acerca de nuevas configuraciones sobre los conceptos de soberanía y ciudadanía y sus posibles límites, en virtud de su aparente 
confrontación con otros conceptos (derechos humanos, comunidad internacional, etc.). No obstante, en todas estas discusiones hay un común denominador: la admisión de facto y de jure de la legitimidad de las fronteras.

No es sencillo, como se puede apreciar, encontrar perspectivas científicas o políticas en donde se inicie la discusión de las fronteras bajo la premisa de que tal vez no son necesarias en la conformación de un orden mundial o que carecen de legitimidad.

Por su parte, y partiendo de la base de que el concepto de frontera no es un elemento monopolizado por la Ciencia Política o el Derecho, otras áreas de estudio como la Geopolítica también la han observado desde diferentes corpus y filiaciones teóricas. La Geopolítica estableció una visión del Estado-nación como organismo vivo, de tal suerte que la frontera representaba su piel y era además la institución por la que se reflejaba la expansión de un territorio; empero, estas expansiones solo se justificaban respecto a zonas políticamente valiosas, como regiones donde proliferan determinados recursos naturales (Arriaga, 2012, p. 79). De modo paralelo, Semple (1911 en Arriaga, 2012, p. 79) afirmó -desde una visión geopolítica- que existen cuatro clases de fronteras: racial, cultural, lingüística y política.

No deja de ser llamativo que las fronteras raciales, culturales y lingüísticas se han ido estrechando en virtud de actividades trasnacionales practicadas por las diásporas de personas migrantes de diferentes nacionalidades y su contacto e incidencia en los territorios de origen. El transnacionalismo es definido por Valdez y Balslev (2007) como "las prácticas que reconstruyen una idea de comunidad basada en una percepción cultural de pertenencia y obligación mutua, clave para entender la construcción de comunidades y la vida social fuera de las fronteras” (p. 200). 
El fenómeno de la globalización también ha aminorado lo robusto de este tipo de fronteras a través de procesos de multiculturalidad. Sin embargo, y por lo que respecta a la frontera política, esta ha pasado por un procedimiento de flexibilización respecto a capitales, información y servicios, consolidándose incluso a través de acuerdos comerciales de naturaleza multilateral; no obstante, esa misma laxidad no ha sido empleada al tratarse de personas que cruzan dichas fronteras políticas.

Tomando en consideración toda esta vasta información emanada de variados enfoques del conocimiento (Derecho, Relaciones Internacionales, Ciencia Política y Geopolítica), se estima que ninguna de ellas ha guardado un espacio para cuestionar la existencia o legitimidad de las fronteras por medio de una postura reflexiva, crítica y que no dé por sentado el actual estado de las cosas. Es por ello por lo que en este trabajo se extraerá de las perspectivas jurídicas y políticas la reflexión referente a las fronteras, para encauzarla hacia un análisis moral que indague en su justificación o legitimidad a partir de diferentes teorías sobre filosofía moral y ética.

\section{Argumentos morales para la justificación - o no- de la existencia de fronteras}

En este trabajo se partirá de la diferenciación que Dworkin (2014, p. 239) expuso sobre las directrices éticas y morales; siendo las primeras pautas que determinan la forma en cómo debemos vivir nosotros mismos, y las segundas, estándares bajo los cuales tenemos que tratar a las demás personas. Al tratarse de un análisis moral, se abordará, en términos de diversas doctrinas filosóficas, cuáles serían los argumentos morales que tendrían -o no tendrían- los Estadosnación para justificar la legitimidad de las fronteras y todas las consecuencias que se derivan con el reconocimiento de su existencia. 
Si se parte de la diferenciación de Dworkin (2014, p. 239) para entender a las normas morales como aquellas que dictan el modo en cómo debemos tratar a las demás personas, el argumento central a discutir consiste en respondes dos preguntas: ¿Cómo se trata actualmente a las personas migrantes que ingresan a un país que no es el de su origen y no lo hacen por las vías regulares existentes? ¿Desde cuál teoría ética se sostiene el rechazo de personas migrantes a un país distinto al de su origen? En estas interrogantes hay tres subargumentos que se deberían resolver para clarificar el panorama: a) desde un punto de vista deontológico ‘es moralmente incorrecto ingresar a un país del que no se es nacional?; b) ¿lo que vuelve inmoral el acto de migrar es no hacerlo por las vías legales?, y c) ¿se deberían conocer las razones que motivan las acciones de las personas migrantes antes de establecer un juicio moral sobre sus conductas?

\section{a. Primer subargumento}

Kant (1988, pp. 49-58) aducía que el principio de la moralidad no se compone de nuestros criterios subjetivos o de nuestras inclinaciones y sentimientos, sino de leyes objetivas que dictan lo que debemos -y no lo que anhelamos- hacer. Esta afirmación de Kant (1988, pp. 49-58) significa que nuestros sentimientos solo tienen valor en nuestra vida privada, pero no podrían tener validez respecto al contexto de los demás.

A este punto de vista de Kant se le puede denominar deontológico, pues estima que los principios morales van más allá de toda inclinación, ya que, de otra forma, cada cual buscaría perseguir sus deseos y no existirían consensos acerca de la moralidad (Kant, 1988, pp. 49-58). Es por ello por lo que estos principios morales emanan de la razón pura, la que no tiene otra fuente sino el entendimiento humano, un entendimiento que se puede evaluar a través de la regla universal, que dicta la calificación de los actos de tal modo que al obrarlos se desee su conversión en leyes universales (o un ejemplo 
de lo que todas las personas deberían de hacer en esos casos), de lo contrario, los actos no se justificarían y serían inadmisibles para la moral (Kant, 1988, pp. 49-58).

La ayuda hacia personas que huyen de entornos críticos donde impera la violencia generalizada y las violaciones sistemáticas de derechos humanos, que en este caso residiría en permitirles el cruce de fronteras y el acceso a otras condiciones de vida, invita a reflexionar con base en la regla universal de Kant; es decir, cuestionarnos si rechazar a un grupo de personas motivadas por la búsqueda de una mejora de vida podría ser constituido como una ley objetiva, producto de un consenso moral universal. Si invirtiéramos los roles y los países desarrollados -o receptores históricos de personas migrantes- tuviesen que huir (migrar) intempestivamente de su territorio por causas de desastres naturales o problemas de medio ambiente y cruzar una frontera: ¿qué tan sostenible seguiría siendo el rechazo como una ley universal? ¿Se seguiría categorizando dentro de la incorreción el acto de migrar o pasar una frontera? ¿Seguirían teniendo sentido moral las fronteras?

Para sumar más elementos a la posible resolución de este primer subargumento, es menester hacer alusión a que en varios países (Estados Unidos, Canadá, etc.) existen políticas migratorias selectivas que permiten solo el ingreso de quienes reúnen algunas características profesionales, etarias u ocupacionales, omitiendo en estos casos la inadmisibilidad moral del acto de migrar (como sí se da en contra de quien migra de modo irregular). Estas políticas migratorias son aquellas: "que a partir de la acción unilateral del Estado determinan de forma indirecta las condiciones de «elegibilidad» de los candidatos a la inmigración y condenan a ciertas categorías de inmigrantes a la clandestinidad” (Massey y Durand, 2003 citado en López, 2005, p. 30).

En otras palabras, tal parece que la acción de desplazarse a un país del que no se es nacional y pasar una frontera no resulta per 
se inmoral -desde una óptica deontológica de los Estados-nación-, pues de ser así, no se justificaría bajo ninguna causa, incluso si se tratara de personas que en apariencia serían de más "utilidad" para un país, pues la perspectiva deontológica no realiza los juicios morales a través del análisis de los resultados obtenidos con posterioridad a la ejecución de un acto.

De hecho, como quedará expuesto en ulteriores explicaciones de este trabajo, el punto de vista deontológico u objetivismo moral (imperativos categóricos) ha sostenido una disputa constante contra el utilitarismo; por tanto, no se pueden establecer convergencias analíticas entre estas dos perspectivas éticas al escudriñar un acto (en este caso el acto de migrar), pues, al hacerlo se corre el riesgo de cometer graves contradicciones argumentativas.

Desde una óptica distinta, existe otro imperativo categórico de Kant (1988, pp. 49-58) que dicta la prohibición del uso de las personas como medios u objetos para alcanzar determinados fines, pues los individuos son fines en ellos mismos. Por lo que, vistas a través de estas vertientes, las políticas migratorias de algunos Estados-nación que permiten el ingreso exclusivo de personas extranjeras que se adecuen a ciertos lineamientos sociodemográficos o de otra índole vulneran este imperativo categórico. La transgresión de este imperativo es dable toda vez que la selectividad de estas políticas persigue ciertos propósitos; por ejemplo, que las personas migrantes ocupen cargos laborales de los nichos de mercado donde se requiere mano de obra, es decir, se les está empleando como medios para obtener metas definidas estatal o políticamente.

En el caso mexicano hay algunos ejemplos como el Programa Bracero de 1942, que refiere a la época en que Estados Unidos permitió el ingreso de muchos nacionales mexicanos para que se emplearan en sus granjas. Lo mismo sucede con aquellas políticas 
canadienses que trajeron como resultado el caso del Programa de Trabajadores Agricolas Temporales y con otras políticas que imperan en algunos países y que permiten el ingreso de personas extranjeras en situaciones de bajos índices de natalidad con la finalidad de elevar la reproducción humana.

El primer subargumento ha quedado aparentemente resuelto, pues si se partiera de la premisa de que los Estados-nación apelan a los principios deontológicos o de objetivismo moral para rechazar el ingreso de personas extranjeras a un país, este rechazo no tendría por qué hacer excepciones. Sin embargo, en las políticas migratorias de algunos Estados-nación que son reconocidos como lugares de destino frecuentes para la inmigración indocumentada, se advierte una clara selectividad y, por ende, excepciones a la regla.

Por ejemplo, un caso ilustrativo es el de Canadá, que cuenta con un sistema de puntos sobre los que se eligen las características de los inmigrantes que pueden traspasar de modo regular la frontera, en función de los requerimientos de su mercado laboral. En resumen, el cruce de una frontera como tal parece no ser un acto moralmente inadmisible.

\section{b. Segundo subargumento}

El segundo subargumento estriba en analizar si lo que repercute en la evaluación moral del acto de ingresar a un país del que no se es nacional es que se dé a través de medios no permitidos por la ley. De tal suerte que, el Estado-nación discrecionalmente condiciona los supuestos por los que una persona puede ingresar de manera regular a su territorio (traspasar su frontera), los que generalmente están sustentados -como se ve en el caso canadiense- en aspectos que le produzcan una "utilidad" o subsanen alguna deficiencia (mano de obra, conocimiento, tecnología, crecimiento demográfico, etc.). 
Esta perspectiva que justifica el rechazo de ciertas personas para ingresar a un país del que no son nacionales, pero aprueba el de otras con basamento en sus perfiles laborales, profesionales o etarios, hace remembrar a la doctrina filosófica del utilitarismo. Esta doctrina fue propuesta por Bentham (1836, pp. 21-22) y se fundamenta en el principio de la utilidad, en otras palabras, en la noción de que la calificación de un acto como bueno o malo, digno e indigno, es en proporción a su tendencia a acrecentar o disminuir la suma del bien colectivo (dicha pública).

Si se cambiara el enfoque de análisis de un fenómeno como la migración indocumentada -de deontologismo a utilitarismo-, seguiría siendo cuestionable legitimar moralmente el rechazo, pues el mismo Bentham (1836, pp. 21-22) refiere que la virtud habitual en el ser humano gravita en la repetición de actos de omisión o comisión que tengan por finalidad la producción del mayor beneficio a un mayor número de personas (y no solo el placer individual). En ese sentido, negar el acceso a personas por la sola ausencia de documentos migratorios, más allá de conseguir una supuesta utilidad al país receptor, termina por afectar millones de vidas en el mundo, por violentar derechos, por coartar futuros, etcétera, puesto que son más los países expulsores que los receptores de flujos migratorios. Lo que nos obliga a preguntarnos: ¿cuál es el principio de utilidad en esta decisión política de rechazo?

De modo paralelo, si incluimos argumentos de naturaleza económica en el utilitarismo, vale la pena mencionar que países como Estados Unidos han invertido más de 219 millones de dólares en el control de la inmigración durante los últimos 30 años, sin que esto haya producido la eliminación de movilidades humanas (Meissner, Kerwin, Chishti y Bergeron, 2013).

Otra dimensión de análisis consiste en advertir que el juicio moral acerca de los desplazamientos entre fronteras se basa en la 
infracción de un orden jurídico o normativo que estipula de modo preliminar los tipos de movilidades humanas que son permitidos por la legislación y cuáles se convierten en actos que la transgreden. Empero, asumir a la ley positiva como un modelo moral, en principio, irrumpiría con el cálido debate filosófico relativo a las relaciones -o no- que guarda el Derecho con la Moral, que además es un tema todavía en construcción. Por otra vía, eliminaría la posible discusión moral de muchas figuras jurídicas -pasadas y recientes-, llevándonos al grado de una aceptación tajante del estado de las cosas sin mayor réplica.

De acuerdo con Himma (2014, p. 355), las bases conceptuales del positivismo jurídico son tres tesis: 1) la social, 2) la de convencionalidad y 3) la de la separabilidad; esta última se fundamenta en la negativa de una relación necesaria entre el Derecho y la Moral. De allí que persistan diversas clases de positivismo jurídico, primordialmente los incluyente y excluyente.

Desde los escolásticos y el iusnaturalismo ya persistía una resistencia para aceptar tajantemente los contenidos jurídicos como un marco de moralidad. En ese contexto versa la conocida frase de Tomás de Aquino: lex iniusta non est lex (una ley injusta no es una ley). Esta frase si bien es cierto no hace alusión a trastocar la validez jurídica de la ley, sí señalaba su contenido inmoral e injusto, lo que producía como consecuencias: su imperfección, por un lado, y, por el otro, la no obligatoriedad moral para las personas de cumplir con lo propuesto por la norma jurídica (Seoane, 2002, p. 763).

El hecho de que enormes cantidades de personas pretendan cruzar las fronteras del mundo a pesar de las diferentes dificultades, y lo cada día más hostil que es la protección de las divisiones territoriales, y arriesguen su seguridad y vidas (hostilidades crecientes, políticas proteccionistas, violencia, etc.), o que tomen algunas precauciones y se conviertan en actores políticos, estableciendo estrate- 
gias de protección en el camino, como la conformación de éxodos para visibilizar el trayecto y protegerse conjuntamente, es indicativo de que hay algo más que motivos económicos.

La obligación moral de salvaguardar su vida o la de sus familias y abandonar lugares de alto riesgo -como sus países de origen- es más fuerte que la obligación jurídica de abstenerse de traspasar una frontera si no se cuenta con documentos migratorios. Dicho en términos de Weber (2014, p. 104), no cruzar una frontera por las vías jurídicas es un acto de omisión legal, pero no legítimo, cuando las condiciones de vida te orillan a experimentar la obligación moral de desplazarte y traspasar una frontera.

Al profundizar en la opinión de diversos autores, desde distintas disciplinas del conocimiento, queda claro que la ley jurídica no es una directriz de moralidad. Por consiguiente, es complejo afirmar que las personas migrantes sin documentación que cruzan una frontera trastocan por ese solo hecho las pautas de carácter moral, puesto que infringir una ley positiva por sí mismo no representa necesariamente lo anterior, ya que la vulneración a estas reglas jurídicas pudiera traer más beneficio colectivo (enfoque utilitarista), o bien la norma legal puede contar con un contenido injusto y no ameritaría la obediencia de las personas (enfoque iusnaturalista); aunado a que, a partir de la Sociología, las legislaciones no son legítimas -y solo son legales- hasta en tanto no sean observadas por la comunidad como el principal referente conductual.

El segundo subargumento también quedaría aparentemente resuelto, en términos de la estructura y marco de análisis optado en este trabajo, ya que desde ninguna de las corrientes de la filosofía moral y la filosofía jurídica observadas (utilitarismo, iusnaturalismo, sociología jurídica) bastaría la violación de la norma jurídica para aseverar la inmoralidad de un acto; por lo tanto, no se puede interpretar desde estas bases teóricas que la migración irregular o indo- 
cumentada es inmoral, al menos no por el solo hecho de trasgredir una norma de tipo jurídica.

En atención a ello, es menester puntualizar la atención hacia el tercero de los subargumentos, que tiene como objetivo esclarecer si en una valoración o juicio moral sobre la migración -y el acto de pasar una frontera de modo irregular- es necesario conocer las razones que las motivan.

\section{c. Tercer subargumento}

En los inicios del estudio del fenómeno migratorio prevalecieron las teorías economicistas para explicar -o intentar explicar- las causas que estaban detrás de las decisiones de las personas para emigrar; tales como el enfoque económico neoclásico, que establecía que el motor de la migración era la búsqueda de un equilibrio en las diferencias salariales y de condiciones de trabajo de los Estadosnación (sobre todo de los expulsores y receptores), y, por lo tanto, se trataba de decisiones netamente individuales y por razones laborales (Massey et al., 2008).

Por su parte, el enfoque de la nueva teoría económica de la migración sustituyó lo individualizado de la decisión por una estrategia devenida de la unidad familiar, que tiene como finalidad aminorar los riesgos en torno a los ingresos familiares. No obstante, las razones seguían siendo de índole laboral (Massey et al., 2008). Otras teorías como la teoría de los sistemas mundos cuestionaban que estas decisiones se asumieran desde una perspectiva microeconómica y designaban un mayor peso a fuerzas o factores de tipo estructural tanto a nivel nacional como internacional (Massey et al., 2008).

Hay muchas otras teorías desde diversas áreas del conocimiento que han intentado explicar los motivos que se encuentran de trasfondo respecto a las movilidades humanas; sin embargo, para los 
efectos prácticos se han tomado únicamente estas tres como marco de referencia para intentar responder los objetivos trazados al inicio de este texto.

Con el avance de los Estudios de Migración se tornó menester no solamente indagar en las causas que -en apariencia- ocasionaban variadas movilidades humanas, sino también atender aquellos aspectos que perpetúan a la migración y que además consolidan algunos flujos migratorios históricos. De igual manera, otro cambio en el análisis del fenómeno migratorio fue desprender del núcleo causal a los argumentos económicos o laborales y aludir con más frecuencia elementos relacionados con la violencia, los desastres naturales, la discriminación por la pertenencia a un grupo en situación de vulnerabilidad, la violación de derechos humanos de modo sistemático, entre otros.

Como se puede apreciar, las causas que han acompañado el inicio y la perpetuación de los movimientos migratorios se asocian con factores detonantes que producen que el individuo -más allá de decisiones individuales, familiares o supeditadas por factores estructurales- se vea en el apremio de abandonar su país de origen. Difícilmente una persona que goza de las condiciones básicas de vida y de los derechos fundamentales intentará escapar de un contexto con estas características. Son mayormente las condiciones de sus contextos de origen las que generan esta clase de movilidades y las que han persistido en las regiones históricas de la emigración. Como el caso de bolivianos en Argentina, haitianos en República Dominicana, mexicanos en Estados Unidos y centroamericanos (principalmente guatemaltecos, hondureños y salvadoreños) hacia Estados Unidos. Debiendo estos últimos, en todos los casos, transitar o residir temporalmente en territorio mexicano.

Lo anterior no quiere decir que no existan otras movilidades humanas que salgan de estas perspectivas, sino que, en efecto, para 
la valoración moral de un acto es necesario conocer las razones que explican la intención de traspasar una frontera jurídico-administrativa. Es justo en atención a las motivaciones detrás de las movilidades humanas que se ha gestado la creación de ciertas instituciones jurídicas que permiten ingresar a personas extranjeras a otro país con fines de residencia temporal e inclusive permanente; tales figuras son la condición de refugiado y el asilo político. En estas figuras jurídicas se exige -con algunas variaciones en las políticas de cada país- que las personas acrediten persecuciones por razones políticas, religiosas o su pertenencia a un grupo social determinado o bien demuestren que su vida corre peligro si regresan a su país de origen.

La Ley sobre Refugiados, Protección Complementaria y Asilo Politico en México (2014) permite solicitar la condición de refugiado a personas extranjeras que son perseguidas por motivos de raza, religión, nacionalidad, género o pertenecen a determinados grupos sociales, mientras que el asilo político lo define como la protección que se le otorga a un extranjero perseguido por motivos o delitos de carácter político.

Empero, abordar a la migración únicamente en referencia a movilidades que son producto de condiciones críticas en los lugares de salida de la emigración es simplificar la variedad de motivaciones que componen al fenómeno migratorio. ¿Qué sucede con aquellas personas que solo tienen como objetivo aumentar sus ingresos salariales, conocer otros lugares o simplemente cumplir con sus proyectos de vida? Sobre ellos ipodríamos hablar de que su ausencia de motivaciones -supuestamente justificables- es causa suficiente para categorizar el acto de cruzar una frontera sin documentación migratoria como inmoral?

Todo lo anterior nos conduce a profundizar en lo que Rosell (2013) ha nombrado: el primado de la voluntad, que reposa en la contemplación de que: "Toda acción debe ser moralmente evaluada 
exclusivamente en relación con el signo de la voluntad (motivo, intención) por la que el agente lleva a cabo (o intenta llevar a cabo) esta acción” (Rosell, 2013, p. 122). Sin embargo, se ha podido advertir del estado del arte de los estudios de migración que, en el ámbito de las decisiones para emigrar, hay una gran multiplicidad de motivos -o intenciones- por los que los agentes realizan la conducta analizada. A esto habría que sumar que la voluntad de las personas extranjeras al ingresar a otro país está condicionada por una suerte de factores estructurales que no permiten hacer una justa valoración de todos los casos.

Por ejemplo, no basta con que una persona tenga la voluntad o el deseo de cruzar una frontera jurídico-administrativa, sino que en todo caso requiere de encuadrarse en alguno de los supuestos legales de la migración regular o tener los ingresos para tramitar tales documentos migratorios. Muchas personas migrantes no cumplen con estos dos requisitos y, por lo tanto, más allá de sus motivaciones -cualesquiera que fueran- no podrían, en términos jurídicamente permisibles, ingresar a otro país. Su ingreso a un Estado-nación del que no son nacionales depende entonces de la política migratoria aplicable al caso concreto o de decisiones que van más allá de lo individual.

De forma paralela a la supeditación de la voluntad o intención del agente potencial a ingresar a un país distinto al de su nacimiento por las políticas migratorias, otro obstáculo para efectuar un análisis justo de la valoración moral del acto de cruzar una frontera sin documentos migratorios reside en que gran parte de las movilidades humanas -principalmente las de los últimos años- se inscriben dentro de las migraciones forzadas, que tienen como característica puntual la ausencia de la voluntad. Por consiguiente, emplear la voluntad o intención de las personas migrantes que intentan cruzar una frontera para su calificación moral implicaría hacer un análisis sesgado, injus- 
to y que violaría el antiguo principio aristotélico de "tratar igual a los iguales y desigual a los desiguales".

El tercer subargumento quedaría de algún modo resuelto, pues es imposible realizar una valoración completa cuando las piezas están previamente condicionadas por una estructura definida, que en este caso deviene de las políticas y decisiones de los Estados-nación o bien de las condiciones de los lugares de salida. En tal sentido, es inviable minimizar algunas razones - de las personas migrantes- $y$ enarbolar otras, pues estas motivaciones no son del todo genuinas al depender de dos fuentes estructurales: a) las definiciones acerca de quién puede -y quién no puede- ingresar a un Estado-nación desde sus constituciones y políticas públicas, y b) la involuntariedad de diversas movilidades humanas resultado de condiciones críticas en los lugares de procedencia.

Aun si se extendiera el análisis a otra doctrina de la moral para la calificación de los actos humanos -en tanto su corrección o incorrección- como el consecuencialismo, habría serias dudas para la legitimidad de las fronteras. El consecuencialismo es una teoría ética que considera que lo virtuoso de los actos humanos reside en alguna finalidad valiosa que persigan, es decir, estima que las acciones se juzgan por el estado de las cosas que de ellos se sigan (Cejudo, 2010, p. 5).

Bajo esta noción, una política migratoria que criminaliza el traspaso de fronteras sin documentación termina por generar menos bienestar en el mundo, o al menos deja el estado de las cosas igual, al negar oportunidades a muchas personas que su único conflicto fue nacer en un país donde se carece de condiciones elementales de vida.

Se ha intentado a través del escudriñamiento de estos tres subargumentos contestar la pregunta del argumento central; para ello se ha recurrido a algunas de las doctrinas de la filosofía moral y otras perspectivas jurídicas y sociológicas. Sin embargo, no se ha 
encontrado ninguna que sostenga la legitimidad de la contención migratoria a partir del cierre de fronteras. Puede que existan otras y este trabajo abre el debate, pero encontrarlas, ha quedado claro, no es una labor sencilla.

Lo anterior lleva a repensar en nuevas formas de tratar y regular el fenómeno migratorio, principalmente en contextos políticos que se asumen como sociedades democráticas y Estados de derecho. El cierre de fronteras para lo que se ha construido discursivamente como migración irregular ha sido una política fallida y seguramente su no adscripción a alguna corriente moral habrá incidido en estos resultados.

\section{Conclusiones}

Una vez que se ha analizado la existencia o legitimidad de las fronteras desde varias ópticas de la moral y de la filosofía del derecho -además de la sociología de Weber-, ya se cuenta con mayores elementos para responder las dos preguntas que atañen al argumento central de esta discusión: ¿Cómo se trata actualmente a las personas migrantes que ingresan a un país que no es el de su origen y no lo hacen por las vías regulares existentes? ¿Desde cuál teoría ética se sostiene el rechazo de personas migrantes a un país distinto al de su origen?

Cuando un Estado-nación opta por el rechazo para tratar a comunidades que forman parte de movilidades humanas que no poseen documentación migratoria, esta decisión no se sostiene cuando es sometida al imperativo categórico de Kant sobre la regla universal. Tal insostenibilidad opera no solamente porque al invertir los roles seguramente estos países -que hoy son receptores de personas migrantes- desearían ingresar a toda costa a otro país y, por ende, cruzar una frontera, sino también porque las propias políticas de estos Estados-nación -al menos las de la mayoría- estipulan excepciones 
donde estiman admisible el ingreso de personas extranjeras bajo determinadas condiciones, por tanto y por ese solo hecho, ya no puede ser asimilada esta regla como de carácter universal.

Por su parte, estas políticas migratorias selectivas que enfatizan en características específicas en los perfiles de las personas extranjeras "deseables" vulneran igualmente el segundo imperativo categórico de Kant, que consta en la prohibición de estimar a una persona como un objeto para alcanzar algunos objetivos. Todas las políticas públicas en materia migratoria que descansan en la selectividad necesariamente aluden a propósitos definidos de los Estado-nación, ya sea con la pretensión de poblar mercados de trabajo, abastecer servicios en áreas donde no hay personal nativo o incluso aumentar los índices de reproducción y natalidad. En todos estos casos, el individuo está siendo objetualizado, pues solo representa un medio para llegar a unos propósitos. En conclusión, el rechazo de estas comunidades migrantes no es una respuesta factible desde el deontologismo.

Ahora bien, si se apela al utilitarismo como doctrina para calificar el acto de rechazar a estas poblaciones, de cualquier manera, se transgreden las bases morales de esta perspectiva, pues esta reposa en el concepto de dicha pública, es decir, en el mayor bien para el mayor número de personas. Al cotejar los daños y ventajas propiciados por estas políticas y la cantidad de países que históricamente son reconocidos como receptores y expulsores, el recuento dentro una política contenciosa y selectiva, termina por producir más perjuicios que beneficios, por afectar más derechos que los que protege $-\mathrm{O}$ intenta proteger-y por causar detrimentos a más personas de las que les confiere alguna ventaja. De hecho, si invocamos los aspectos más extremos del utilitarismo y se traen a colación argumentos de naturaleza económica, se han perdido mayores cantidades de dinero en la protección de las fronteras que lo que se ha ganado con ellas -ya se mencionó el caso concreto de Estados Unidos-. 
En otro sentido, si la calificación del acto de migrar como inmoral es debido a que infringe una norma jurídica, se torna cuestionable en dos aristas: la primera, en virtud de que la norma jurídica no es un parámetro de moralidad per se, pues ya desde los escolásticos quedaba claro que el iusnaturalismo había evidenciado la presencia de leyes injustas o al menos carentes de algún valor moral y, por ende, tales normas no merecían -desde el enfoque iusnaturalista- la obediencia por parte de los "obligados". La segunda arista nace desde el enfoque sociológico de Weber (2014, p. 104), al diferenciar la legalidad de la legitimidad, siendo esta un concepto mayúsculo, pues significa que las personas de un núcleo social han admitido una regla como una creencia socialmente compartida y la perciben obligatoria, por ello, la meta de la legalidad es convertirse tarde que temprano en legitimidad.

Hay otras posturas morales que realizan la valoración de los actos humanos tomando en contemplación las intenciones o motivaciones que tienen los agentes de la conducta, como el caso del primado de la voluntad (Rosell, 2013, p. 122). Sin embargo, para los flujos migratorios no existe una sola motivación, ya que esta, en sí misma, es un fenómeno multicausal y ello complejiza la posibilidad de hacer una valoración de cuáles causas sí y cuáles no ingresarían en el ámbito de la corrección moral. Aunado a lo anterior, se tiene el caso de las migraciones forzadas, donde claramente impera la involuntariedad en los actos: ‘cómo juzgar moralmente y desde la voluntad un acto que se ejecuta de manera forzada? A este tipo de preguntas complejas se arriba cuando se escudriña el acto de migrar y traspasar fronteras desde este posicionamiento moral.

Existen otros aspectos que terminan por enmarañar aún más el hecho de calificar el acto de cruzar una frontera como moral o inmoral que estriban en: 1) la supeditación de las decisiones individuales de las personas migrantes a las políticas y normas legales definidas por los Estados-nación receptores y, por lo tanto, la ausencia 
de una intención genuina con probabilidad de materialización de la conducta -que es difícil de evaluar a la luz del primado de la voluntad- y 2) la imposibilidad de evaluar a quienes no tienen motivos críticos -por ejemplo, para solicitar refugio o asilo político-, sino únicamente son movidos por la persecución de proyectos personales o simple turismo. Como se puede apreciar, hay muchos factores que no permiten evaluar el acto de pasar una frontera por medio de esta noción moral.

Para complementar el estudio de las fronteras a la luz de las principales teorías morales es inexorable aludir al consecuencialismo en esta discusión. No obstante, ha quedado claro que los objetivos que pueden llegar a perseguir aquellas políticas que criminalizan el acto de traspasar una frontera traen como consecuencia un estado de las cosas crítico, hostil y en condiciones complejas en los lugares históricos de expulsión de personas migrantes. De manera que no es del todo identificable el propósito positivo que persiguen estas políticas migratorias, ya que el consecuencialismo incluso nos conmina a ir en contra de nuestros deseos para perseguir la opción con la que el estado de las cosas culmine de mejor manera, como en el caso del cura sobre el que escribió Unamuno en 1930 que se sintetiza de la siguiente forma:

Cejudo (2010, pp. 3-4) al explicar el consecuencialismo como doctrina moral nos hace remembrar la historia del cura de una aldea que escribió Unamuno en 1930 en San Manuel Bueno, mártir. Esta historia narra un dilema moral de un sacerdote que ha dejado de tener fe, pero sigue compartiéndola con los feligreses. Llega a la disyuntiva de no saber qué sería correcto hacer: atender a un punto de vista deontológico y de principios y no mentir, aunque eso pudiera implicar resultados negativos o mentir para efecto de que los feligreses sigan creyendo en el valor de la verdad, es decir, asumir una postura consecuencialista. El caso como se puede ver es muy ilustrativo para comprender no solo las características del con- 
secuencialismo, sino la pugna de las diversas corrientes morales en situaciones fácticas.

Para concluir, no se ha encontrado en este trabajo alguna doctrina moral que justifique las fronteras y que, por tanto, les confiera legitimidad para su existencia. Las fronteras en la actualidad se han transformado en una construcción social que le entrega facultad a los Estados-nación para convalidar desigualdades y establecer políticas migratorias a expensas de utilidades unilaterales. Ni desde el deontologismo, el utilitarismo, el consecuencialismo, o el primado de la voluntad se encuentran argumentos morales suficientes para legitimar a las fronteras o para rechazar el ingreso de una persona a otro país del que no es nacional, sin documentación.

Incluso si se extiende el análisis a doctrinas iusfilosóficas o sociológicas, sigue pendiente la localización de argumentos torales para la incorrección del acto de migrar o cruzar una frontera. En conclusión, la justificación o legitimidad de las fronteras no nace del ámbito de moralidad y solo existe porque los Estados -de forma unilateral- han diseñado en sus políticas y normas internas, conceptos que legalizan estas prohibiciones, empero, lo legal no es sinónimo de lo legítimo.

\section{Referencias}

Arriaga, Juan (2012). El concepto frontero en la geografía humana. Perspectiva geográfica, $17,71-96$.

Bentham, Jeremías (1986). Deontología o ciencia de la moral. España: Librería de Mayen y sobrinos.

Bustamante, Jorge (2002). Migración internacional y derechos humanos. México: Universidad Nacional Autónoma de México. 
Bustamante, Jorge (2018). A dialectical understanding of the Vulnerability of International Migrants. En Batur, P- Feagin, J.R. (Eds.), Handbook of the Sociology of Racial and Ethnic Relations, pp. 161-190.

Carbonell, Miguel (2008). ¿Se justifican las fronteras en el siglo XXI? En Cienfuegos Salgado David- Esquivel Leyva, Manuel de Jesús- Morales Sánchez, Julieta (Eds.), Temas de migración y derecho. México: Fundación Académica Guerrerense, Universidad Autónoma de Sinaloa, Universidad Autónoma de Chiapas.

Carens, Joseph (2009): Extranjeros y ciudadanos. Un argumento a favor de las fronteras abiertas. Isonomía, (30), 53-78.

Carpizo, Jorge (2011). Los derechos humanos: naturaleza, denominación y características. Cuestiones constitucionales, Revista Mexicana de Derecho Constitucional, (25), 3-29.

Carpizo, Jorge, 2012. La Constitución mexicana y el derecho internacional de los derechos humanos, Anuario Mexicano de Derecho Internacional, vol. XII, 2012, pp. 801858.

Cejudo, Rafael (2010). Deontología y consecuencialismo: un enfoque informacional. Crítica, Revista Hispanoamericana de Filosofía, 42(126), 3-24.

Diario Oficial de la Federación (2014). Ley de Refugiados, Protección Complementaria y AsiIo Político, última reforma publicada el 30 de octubre de 2014, pp. 1-20. Recuperado de http://www.diputados.gob.mx/LeyesBiblio/pdf/LRPCAP_301014.pdf

Dworkin, Ronald (2014). Justicia para erizos. México: Fondo de Cultura Económica.

El Colegio de la Frontera Norte (2018). La caravana de migrantes centroamericanos en Tijuana 2018. Diagnóstico y propuestas de acción. México: El Colegio de la Frontera Norte.

Fix-Zamudio, Héctor (2011) Las repercusiones en los ámbitos interno e internacional de la reforma constitucional mexicana sobre derechos humanos del 10 de junio de 2011. Revista Iberoamericana de Derecho Público y Administrativo- Asociación e Instituto Iberoamericano de Derecho Administrativo "Prof. Jesús González Pérez", 11(11), 232-255.

Himma, Kenneth (2014). Positivismo jurídico incluyente. Problema. Anuario de Filosofía y Teoría del Derecho, (8), 353-430.

Kant, Immanuel (1988). Lecciones de ética. España: Editorial Crítica. 
López, Ana (2005). El control de la inmigración: Política fronteriza, selección del acceso e inmigración irregular. Arbor, 181(713), 27-39.

Massey, D., Arango, J., Graeme, H., Kouaouci, A., Pellegrino, A., y Taylor, E. (2008). Teorías de migración internacional: Una revisión y aproximación, Revista de Derecho Constitucional Europeo. ReDCE, (10), 435-478.

Meissner, Kerwin, Chishti y Bergeron (2013). Immigration Enforcement in the United States: The rise of a formidable machinery. Estados Unidos, Migration Policy Institute.

Morales Sánchez, Julieta (2017). Derechos humanos y migraciones: paradojas y reformulaciones en 2017. Ciencia Jurídica, 6(11), 91-118.

Pécoud y de Guchteneire (2005). Migración sin fronteras: una investigación sobre la libre circulación de personas. Migraciones internacionales, 3(2), 137-166.

Porrúa, Francisco (2005). Teoría del Estado. México: Editorial Porrúa.

Rawls, John (2006). Teoría de la justicia. México: Fondo de Cultura Económica.

Rosell, Sergi (2013). Voluntad y responsabilidad moral. Revista de Filosofía, 38(1), $121-$ 138.

Salas, Fernando (2000). Soberanía: ¿el ocaso de un ídolo? IUS ET VERITAS, (21), 43-52.

Seoane, José (2002). La doctrina clásica de la lex iniusta y la fórmula de Radbruch. Un ensayo de comparación. Anuario da Facultade de Dereito da Universidade da Coruña, (6), 761-790.

Valdés José (2015). Globalización vs. soberanía: gobernanza, guerra o progreso y orden mundial. Norteamérica, 10(2), 7-46.

Valdez, Gloria y Balslev, Helene (2007). Migración y transnacionalismo. Experiencias de inmigrantes en el transporte público de San Diego, California, 2004. Región y sociedad, 19, 199-218.

Vargas, Felipe (2018). El vía crucis del migrante: demandas y membresía. Trace, (73), 117133.

Weber, Max (2014). Economía y sociedad. México: Fondo de Cultura Económica. 